\title{
Technical and technological operations for the adaptation of agriculture to global warming conditions
}

\author{
Vladimir Milyutkin*, Vladimir Sysoev, Aliya Trots, I. Guzhin, and S. Zhilzov \\ Samara State Agrarian University, 446409 Ust-Kinelskiy, Samara region, Russia
}

\begin{abstract}
This article is devoted to the improvement of technologies and technical operations for providing agricultural plants with moisture, such as optimal moisture accumulation of both winter precipitation (snow) and summer rainfall and their rational spending, excluding unproductive moisture losses by reducing evaporation because of high soil temperatures, which is typical, according to experts, of global warming.
\end{abstract}

\section{Introduction}

\subsection{Relevance}

The increase in agricultural production, both in Russia and in the world, is the most important thing in the livelihood of people, which places increased demands on agricultural science and agricultural production as a whole.

The problem of the situation: food shortages, world demographic population growth and more frequent negative weather events, which are primarily associated with the so-called global warming.

\subsection{Aim of the research}

The aim of the research is to summarize the world's research and production experience and our own research, conducted at the Samara State Agrarian University (Russia), in order to substantiate the most efficient technologies and technical operations that ensure stable and developing agricultural production in favorable conditions for the development of agricultural crops and in drought conditions with a lack of moisture, which is typical of global warming.

\section{Results of the research}

Drought control, especially soil drought, is a control over desiccation of the root zone due to the long absence of precipitation, insufficient accumulation, high evaporation during overheating of the upper soil layers, which finally leads to low plant productivity [1-3].

One of the effective methods of moisture accumulation is the use of the maximum amount of melt water through intensive snow retention in many regions of Russia, including the Samara region of the Volga Federal District, experiencing a lack of moisture during the growing season. Due to the effective conservation and use of winter moisture, in principle, it is possible to solve its deficit in the spring period. So, with an average annual precipitation of all types of precipitation of $380-450 \mathrm{~mm}$ per year and $30 \%$ of them in winter, about $130-150 \mathrm{~mm}$, it is possible to accumulate the necessary amount of moisture for intensive plant growth in the meter soil layer.

According to many years of the research, snow capture carried out on winter and summer wheat in the different regions of Russia by technical operations gives the following yield increase: $0.2-0.5 \mathrm{t} / \mathrm{ha}$ in the Volga region, $0.3-0.4 \mathrm{t} / \mathrm{ha}$ in the Urals, $0.7-1.3 \mathrm{t} / \mathrm{ha}$ in the Western Siberia (winter wheat); $1-4 \mathrm{t} / \mathrm{ha}$ in the Volga region, $0.3-0.7 \mathrm{t} / \mathrm{ha}$ in the Urals, $0.4-0.7 \mathrm{t} / \mathrm{ha}$ in the Western Siberia (summer wheat).

For snow retention, plant residues (stubble of agricultural crops) conservation after harvesting and strip hedges are effectively used.

Today, the No-Till technology is widely used, in which the stubble remains undamaged by subsurface cultivators, that allows improving snow accumulation, but with traditional harvesting, the stubble remains no more than $0.2 \mathrm{~m}$ high, being a natural barrier to blowing snow high-speed wind gusts (up to $10 \mathrm{~m} / \mathrm{s}$ ). When the remains of stubble are covered with snow with a height of $0.2 \mathrm{~m}$, the snow due to its low specific weight moves freely across the field even at a wind speed of $2-4 \mathrm{~m} / \mathrm{s}$ at an a height of more than $0.2 \mathrm{~m}$.

To create additional barriers in the way of snow moving, an effective method would be to leave stubble of full height to an ear $(0.85-1.5 \mathrm{~m})$, which is possible with the introduction of a harvesting technology for grain crops using the combing method and leaving such crops as sunflower and corn after harvesting (without sunflower anthodiums and corn cobs).

Currently, the industry in different countries and in the Russian Federation produces reapers of various designs for harvesting grain crops by "combing".

In Samara State Agrarian University in accordance with the made inventions [4], a simple, cheap, reliable in

Corresponding author: oiapp@mail.ru 
technology that does not reduce the operational capabilities of serial headers, adapter in the form of an additional tooth rotor, which can be installed in front of the auger rotor on all the harvesters is developed and tested.

Thus, the problem of effective snow retention due to the remaining of all the stubble when using the grain harvesting "combing" method and by leaving the stems of sunflower and corn using the latest strip sowing technology Strip-Till is not a limitation to sowing [5].

Consequently, the newest technologies and technical operations make it possible to create more favourable conditions for the development of crops and level out the crisis weather patterns (severe frosts, wind, blowing off snow from fields, overheating of the upper soil layer and unproductive moisture loss).

To assess the protective properties of snow (the protection of winter crops from freezing), studies have been conducted on the effect of snow depth on the temperature of the surface soil layer (Fig. 1) at different air temperatures.

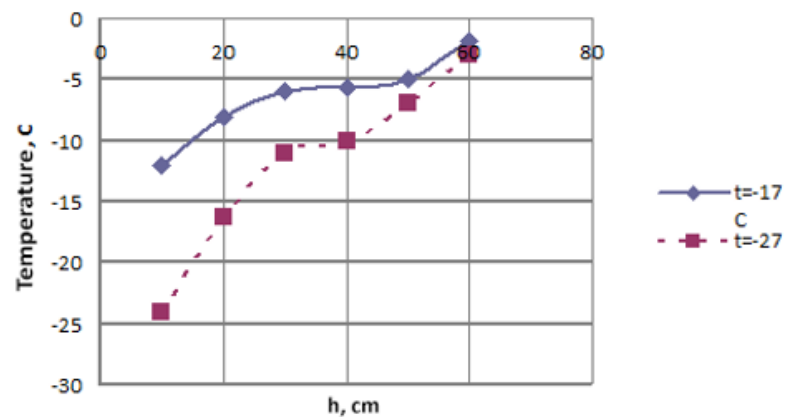

Fig. 1. The effect of snow depth (h) on the temperature of the soil surface at different air temperatures $\left(\mathrm{t}=-17^{\circ} \mathrm{C} ;-27^{\circ} \mathrm{C}\right)$

Numerous scientific studies have established that winter rye can withstand frosts at a tillering depth of up to $-20{ }^{\circ} \mathrm{C}$, winter wheat up to $-16 \ldots-18{ }^{\circ} \mathrm{C}$, and winter barley up to $-120{ }^{\circ} \mathrm{C}$. Our experiments have established that at an air temperature of $-27{ }^{\circ} \mathrm{C}$ these optimum temperatures in the tillering zone are provided by a snow cover of $15-30 \mathrm{~cm}$, which is effectively formed by the full height of straw ("combing" harvesting) or stems of sunflower or corn.

M.E. Cherepanov has shown what height the stubble should be in order to maintain the maximum possible amount of snow with its further maximum absorption, ensuring optimum soil moisture for the spring period [6]. From the results of research and calculations, he cited that it is necessary to leave a stubble $30-40 \mathrm{~cm}$ high for the norm of water retention $(60-80 \mathrm{~mm})$, which was previously impossible, but today thanks to the "combing" harvesting does not cause problems.

The next, unresolved problem is a planting crops in a large amount of uncut mulch without choking the tools, which is, covering the top layer of the earth for better reflection of the light surface compared to the dark soil surface (intensively absorbing heat fluxes), providing lower soil temperature.

The physical meaning of heating the air by solar radiation, penetrating through its layers, is based on the absorption of thermal energy of the sun by the dark soil surface, from which the air is heated, rising to the upper layers, and the soil is heated much more intensively than air.

Our studies have established daily changes in soil temperature and air temperature in the surface layer of $0.5-1.5 \mathrm{~cm}$ (Fig. 2).

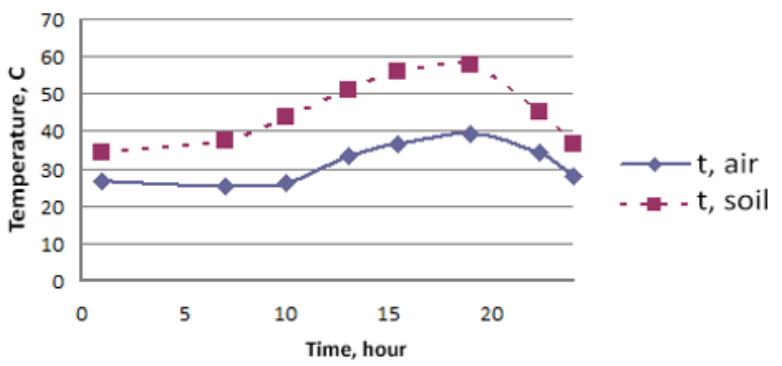

Fig. 2. The change in temperature of the top layer of soil and air in the surface layer $(0.5-1.5 \mathrm{~cm})$ during the day on a hot day (2010, July 29th).

Studies were conducted in the hottest period for the history in the Volga region, in July 2010 in sunny weather. The air temperature at the same time changed from 27 to $37{ }^{\circ} \mathrm{C}$, but the soil warmed up from 20 to 58 ${ }^{\circ} \mathrm{C}$, and as it is known, at a temperature of $42-49{ }^{\circ} \mathrm{C}$ the seed protein begins to break down.

In this connection, we have considered various technologies for the production of agricultural crops with different stubble conditions [3].

Protective from increased solar radiation functions of stubble as well as from heating the soil and unproductive loss of moisture depend mainly on its quantity. The number of mulch is determined by the seeding rate, the density of standing before harvesting the cultivated crop, height and diameter of the stems.

To assess the protective function of stubble, we introduce the so-called coefficient of shelter $K y$, the physical meaning of which expresses the degree of shelter with straw in any of its condition (cut or uncut) and plant residues of the upper layer of the soil. With full shelter without any open soil areas $K y=1$, with some open areas $K y<1$, while covering the surface with straw in several layers $K y>1$.

Analytically, $K y$ is determined taking into account plant density $-\mathrm{n}$ (per unit area), the condition of the crop being harvested (the straw of which will be used to shelter the soil), the length of the straw to harvest $-h$ (with the cut height $-a$ ), the diameter of the straw $-d$. In this case, for a certain area $S$ with full shelter in at least one straw layer, an approximate equality of the area of the material (straw) Sy to be covered with the area of the field $S$ is necessary:

$$
S \approx S y=d \cdot h \cdot N
$$

where $d$ and $h$ are respectively the diameter and the length of the straw; $N$ is the number of straws on the area $\mathrm{S}$.

With a known density of standing culture before harvesting $n=\frac{N}{S}$, the coefficient of shelter is equal to: 


$$
K y=\frac{S y}{S}=\frac{d \cdot h \cdot N}{S}=d \cdot h \cdot n .
$$

Taking into account the variability of the parameters of the formula (2), we express the average coefficient of the shelter $K y$ in terms of the average integral values of the field area:

$$
\begin{gathered}
\bar{d}=\frac{1}{S} \iint_{S} d(x ; y) d s, \bar{h}=\frac{1}{S} \iint_{S} h(x ; y) d S, \\
\bar{n}=\frac{1}{S} \iint_{S} n(x ; y) d S,
\end{gathered}
$$

then $K \bar{y}=\bar{d} \cdot \bar{h} \cdot \bar{n}$.

The dependence of the average coefficient of shelter on the length of the straw before harvesting the agricultural crop is shown in Fig. 3 and 4.

In the calculations, the average density of the plant culture per $1 \mathrm{~m}^{2}$ and the variation of the straw diameter from 2 to $4 \mathrm{~mm}$ (Fig. 3), as well as the variation of the standing density of the crop from 300 to 600 plants per $1 \mathrm{~m}^{2}$ with an average straw diameter of $3 \mathrm{~mm}$, are taken (Fig. 4).

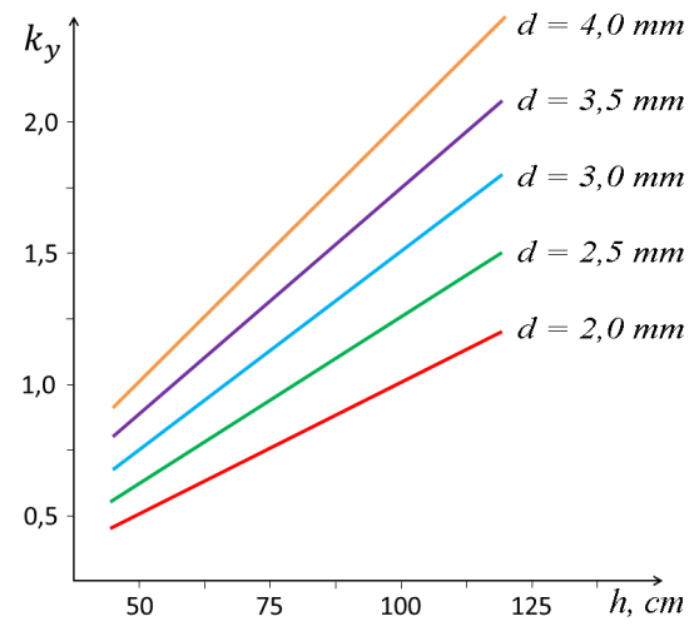

Fig. 3. The change in the coefficient of shelter $K y$ in the thickness of the straw $(d)$ and length $(h)$

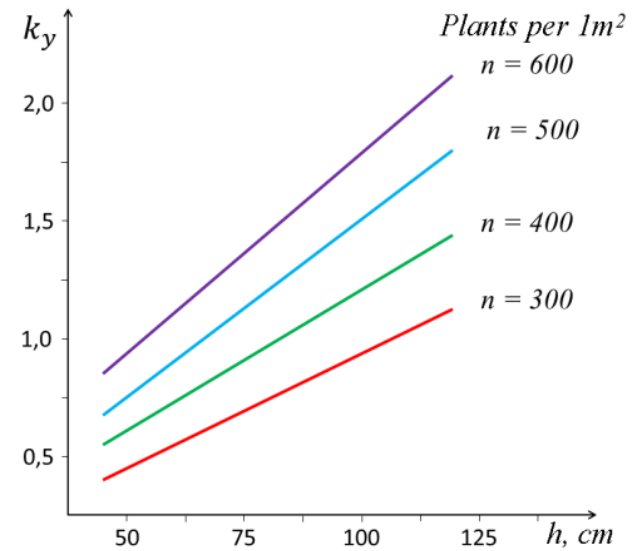

Fig. 4. The change in the coefficient of shelter $K y$ in the height of the stubble $(h)$ and its quantity $(N)$ per $1 \mathrm{~m}^{2}(\mathrm{pcs})$

With average parameters for calculation: $N=5$ million cereal plants per 1 ha for harvesting; $d=2 \mathrm{~mm}$

$h=1 \mathrm{~m}$;

$S y=10000 \mathrm{~m} 2$, which is equal to one ha and at the same time $K y=1$.

With less either density or height, or the length of the straw, or the diameter of the straw, $K y$ will be less than 1 and the soil surface will not be completely sheltered. These areas will be heated by solar radiation intensively, since there will be no protective reflective ability of straw, which will cause an increase in unproductive moisture loss.

To confirm this fact we carried out studies on the chernozem soils of the Volga region (Samara region) to determine the protective properties of straw from overheating of the surface soil layer $(0-10 \mathrm{~cm})$ in the hard dry 2010.

In our experiments in three variants the temperature of the soil in a layer of $0-10 \mathrm{~cm}$ was determined in: $1-$ surface without plant residues (similar to black fallow), 2 - surface covered with $5 \mathrm{~cm}$ mulch; 3 - surface covered with $10 \mathrm{~cm}$ mulch.

At the same time, the air temperature was measured. We chose the sunny days with full solar radiation (the experiments were conducted in August 2010).

In the studies, the air temperature was recorded from 27 to $35^{\circ} \mathrm{C}$ (Fig. 5).

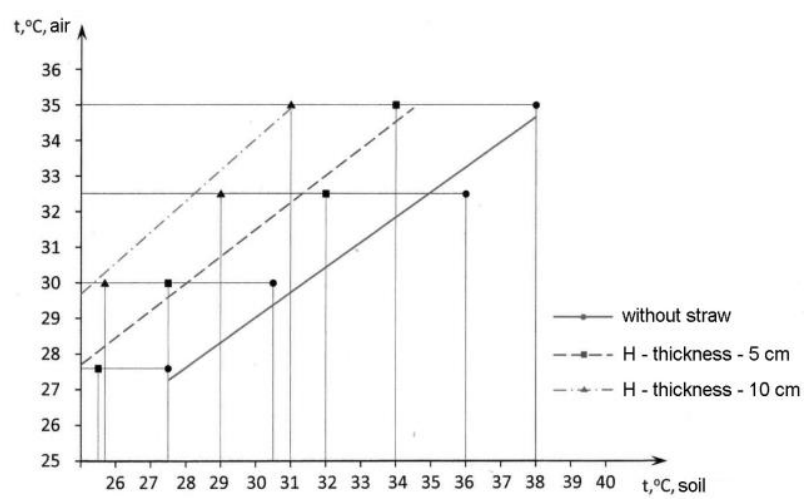

Fig. 5. Dependence of topsoil temperature $(0-10 \mathrm{~cm})$ on the soil surface condition (without straw, $5 \mathrm{~cm}$ mulch and $10 \mathrm{~cm}$ mulch layer) and air temperature

The changes in soil temperature depending on the surface condition and air temperature are shown in Fig. 5, from which it can be seen that the dependence of the upper soil layer temperature on the air temperature and, accordingly, on the intensity of solar radiation is direct in any surface condition. The intensity and nature of changes in soil temperature depending on the state of the surface (open and sheltered with straw of various thickness $\mathrm{H}$ ) are shown in Fig. 6.

At air temperature of $30{ }^{\circ} \mathrm{C}$ the temperature of the soil without any straw was $30.5{ }^{\circ} \mathrm{C}$, covered with $5 \mathrm{~cm}$ of mulch $-27^{\circ} \mathrm{C}$ (lower by $3{ }^{\circ} \mathrm{C}$ ), covered with $10 \mathrm{~cm}$ of mulch $-25.5^{\circ} \mathrm{C}$ (lower by $4.5^{\circ} \mathrm{C}$ ). Straw, therefore, affects the decrease in the action of solar radiation due to its reflection by a lighter surface than the soil and, due to shading of the soil, ultimately reduces its temperature by 4.5 to $5^{\circ} \mathrm{C}$. 


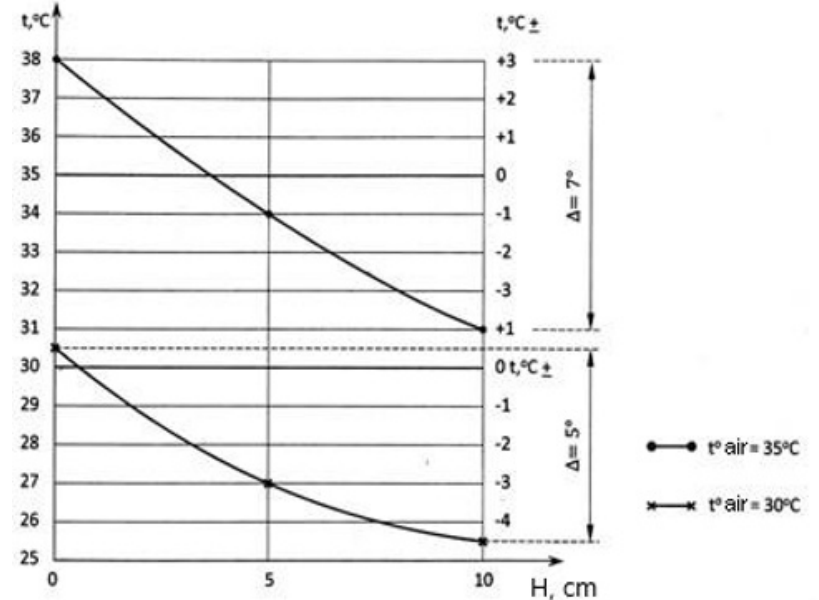

Fig. 6. The influence of the state of the soil surface (without straw, sheltered with $5 \mathrm{~cm}$ mulch or $10 \mathrm{~cm}$ mulch) and air temperature on the soil temperature in root zone $0-10 \mathrm{~cm}$

Moreover, the higher the temperature of the air, the more positive the protective (from solar radiation) properties of straw, covering the soil. So, at air temperature of $35^{\circ} \mathrm{C}$ the temperature in the topsoil layer is higher by $3{ }^{\circ} \mathrm{C}$ on an open surface, lower by $1{ }^{\circ} \mathrm{C}$ at 5 $\mathrm{cm}$ mulch cover and lower by $4{ }^{\circ} \mathrm{C}$ at $10 \mathrm{~cm}$ mulch cover, that is, the change (decrease in soil temperature) is $\Delta=7^{\circ} \mathrm{C}$.

At air temperature of $30{ }^{\circ} \mathrm{C}$, the temperature in the top layer of soil is higher than atmospheric by $0.5^{\circ} \mathrm{C}$ on the open surface, lower by $3{ }^{\circ} \mathrm{C}$ at $5 \mathrm{~cm}$ mulch layer and lower by $4.5{ }^{\circ} \mathrm{C}$ at $10 \mathrm{~cm}$ mulch layer, i.e. the change (decrease in soil temperature) is $\Delta=5^{\circ} \mathrm{C}$.

The Strip-Till technology is highly efficient against the background of high non-crushed grain stubble or sunflower stalks or corn. $0.25 \mathrm{~m}$, treating the soil in them and enclosing mineral and other fertilizers necessary for the purpose and quantity in two layers. The furrow, in which usually tilled crops are sown: corn, soybean, sunflower, etc., has a dark color that warms up well in spring, providing friendly, early shoots. Rows covered with a thick layer of plant residues (Fig. 7) protect the soil from overheating and unproductive loss of moisture, contributing to the optimal state of the plants even in hot weather.

The Strip-Till technology is highly efficient on the background of high uncut grain stubble or stems of sunflower or corn, according to which the cultivatorfertilizer passes in spring along plant residues, cutting the $0.20-0.25 \mathrm{~m}$ wide furrows, cultivating the soil in them and filling in two layers of mineral and other fertilizers necessary for their intended purpose and quantity. The furrow in which usually tilled crops are sown: corn, soybean, sunflower, etc., has a dark color that warms up well in spring, providing early good sprouts. The spaces between the rows covered by thick mulch layer (Fig. 7) protect the soil from overheating and unproductive loss of moisture, contributing to the optimal state of the plants even in hot weather.

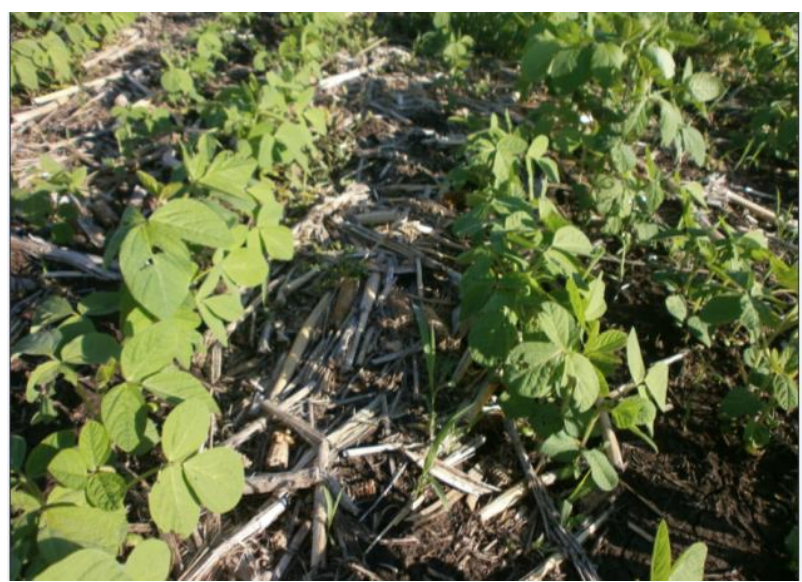

Fig. 7. Soybean sprouts after the corn on Strip-Till technology

\section{Conclusion}

Thus, due to natural, not expensive sources such as the stubble of grain and high-stem tilled crops it is possible to significantly increase the controllability of the process of efficient crop production using new technologies and new agricultural machines even under critical conditions like droughts and under the global warming partially removing their negative effects, strengthening effective water accumulation and reducing unproductive consumption of soil water.

\section{References}

1. S. Li, Y. Li, H. Lin, H. Feng, M. Dyck, Effects of different mulching technologies on evapotranspiration and summer maize growth Agricult. Water Management 201, 309-318 (2018)

2. H. Ram, B. Kumar, N. Aggarwal, J. Kaur, Resourceconserving technologies for enhancing resource use efficiency and crop productivity (Book Chapter) Ecofriendly Agro-biological Techniques for Enhancing Crop Productivity 129-145 (2018)

3. V.A. Milyutkin, V.V. Orlov, G.V. Knurova, V.S. Stenovsky, Effective technological methods in the agriculture, providing optimal moisture growth in the soil and water consumption Bull. of the Orenburg State Agrar. Univer. 6(56), 69-72 (2015)

4. V.A. Milyutkin, N.F. Strebkov, S.A. Solovyev, Z.V. Makarovskaya, Technical solutions for No-Till and Strip-Till technologies Bull. of Orenburg State Agrar. Univer. 6(50), 61-63 (2014)

5. M.E. Cherepanov, Snow retention in conservation agriculture of Western Siberia (Novosibirsk, 1998)

6. V.A. Milyutkin, V. Dolgorukov, Soil-protecting agricultural technologies and equipment for the production of agricultural crops Bull. of Samara State Agricult. Acad. 3, 37-44 (2014) 